\title{
Spatial Pattern Analysis of Sharka Disease (Plum pox virus Strain M) in Peach Orchards of Southern France
}

\author{
Sylvie Dallot, Tim Gottwald, Gérard Labonne, and Jean-Bernard Quiot
}

First and second authors: U.S. Department of Agriculture-Agricultural Research Service, U.S. Horticultural Research Laboratory, 2001 South Rock Road, Ft. Pierce, FL 34945; and third and fourth authors: UMR BGPI, Institut National de la Recherche Agronomique, 2 place Viala, 34060 Montpellier Cedex 1, France.

Accepted for publication 8 July 2003.

\begin{abstract}
Dallot, S., Gottwald, T., Labonne, G., and Quiot, J.-B. 2003. Spatial pattern analysis of Sharka disease (Plum pox virus strain $\mathrm{M}$ ) in peach orchards of southern France. Phytopathology 93:1543-1552.

The spatial pattern of Sharka disease, caused by Plum pox virus (PPV) strain M, was investigated in 18 peach plots located in two areas of southern France. PPV infections were monitored visually for each individual tree during one to three consecutive years. Point pattern and correlation-type approaches were undertaken using the binary data directly or after parsing them in contiguous quadrats of 4,9 , and 16 trees. Ordinary runs generally revealed a low but variable proportion of rows with adjacent symptomatic trees. Aggregation of disease incidence was indicated by the $\theta$ parameter of the beta-binomial distribution and related indices in 15 of the 18 plots tested for at least one assessment date of each. When aggregation was detected, it was indicated at all quadrat sizes and tended to be a function of disease incidence, as shown by the binary form of Taylor's power law. Spatial analysis by distance indices

generally extending from 4 to 14 trees within rows and from 4 to 10 trees perpendicular to the rows, could be interpreted as local areas of influence of PPV spread. Spatial patterns at the plot scale were often characterized by the occurrence of several clusters of infected trees located up to $90 \mathrm{~m}$ apart in the direction of the rows. When several time assessments were available, increasing clustering over time was generally evidenced by stronger values of the clustering index and by increasing patch cluster size. The combination of the different approaches revealed a wide range of spatial patterns of PPV-M, from no aggregation to high aggregation of symptomatic trees at all spatial scales investigated. Such patterns suggested that aphid transmission to neighboring trees occurred frequently but was not systematic. The mechanism of primary virus introduction, the age and structure of the orchards when infected, and the diversity of vector species probably had a strong influence on the secondary spread of the disease. This study provides a more complete understanding of PPVM patterns which could help to improve targeting of removal of PPVinfected trees for more effective disease control.
\end{abstract} (SADIE) showed a nonrandom arrangement of quadrats with infected trees in 14 plots. The detection of patch clusters enclosing quadrats with above-average density of symptomatic trees, ellipsoidal in shape and
Additional keywords: Prunus persica, spatial statistic.
Plum pox or Sharka of stone fruits is caused by Plum pox virus (PPV, genus Potyvirus, family Potyviridae). The main woody hosts of PPV are the fruit-producing species of Prunus, including apricots (Prunus armeniaca L.), peaches (P. persica L.), and European and Japanese plums $(P$. domestica $L$. and $P$. salicina Lindl., respectively). Almond ( $P$. amygdalus Batch) can be experimentally infected by graft and aphid transmission, but trees usually show very few symptoms $(5,8)$. Sweet and sour cherries (P. avium L. and P. cerasus L.) may be systemically infected by a few unique PPV strains $(4,35,36)$. The virus is transmitted by vegetative propagation and is spread in orchards by aphids in a nonpersistent manner, inducing rapidly spreading epidemics. At least 14 distinct aphid species that may or may not colonize Prunus trees were found to transmit the virus in controlled transmission experiments $(1,23,26)$.

To date, four groups of PPV have been identified: PPV-D and PPV-M constitute the two main groups, both widely distributed in Europe and showing significant differences in their epidemiological properties. These two strains differ in disease severity among Prunus spp. and especially in their ability to infect peach

Corresponding author: S. Dallot; E-mail address: sdallot@ushrl.ars.usda.gov

Publication no. P-2003-1020-02R

This article is in the public domain and not copyrightable. It may be freely reprinted with customary crediting of the source. The American Phytopathological Society, 2003. trees after aphid transmission. Fast spreading outbreaks are most often linked to the PPV-M strain $(6,41)$. Competitive natural recombinants between $\mathrm{M}$ and $\mathrm{D}$ strains have been detected in eastern Europe (9). Two other minor groups include apricot isolates from Egypt (PPV-EA) and isolates able to infect cherries systemically (PPV-C) $(36,52)$.

Sharka disease was first detected in Bulgaria in 1915 and since then has spread to most of Europe, the Mediterranean, the Middle East, India, and Chile $(43,45)$. The PPV-D strain was detected in North America for the first time in peach and plum orchards in Pennsylvania in 1999 (27). In June of 2000, PPV-D also was confirmed in Canada, and subsequently, positive trees have been located in all major peach/nectarine production areas of the Niagara peninsula (Ontario, Canada). In France, PPV-D was first detected in 1970 mainly in apricot orchards and was maintained at a very low incidence by strict sanitation programs. A change in the epidemics began in the late 1980s with the detection of unusually rapid spreading infections in peach orchards (41). This change was related to the introduction of the PPV-M strain in southern France. By typing more than 200 virus isolates from the main foci of infection of southern France, a differential distribution of the PPV-D and PPV-M strains was found in apricot and peach orchards; the PPV-D strain was predominantly restricted to apricot orchards, whereas PPV-M was prevalent in peach orchards $(6,41)$. A strict program of disease control by the removal of symptomatic peach trees has been undertaken in France since the detection of this aggressive PPV-M strain in peach orchards. However, no detailed analysis of the spatial pattern of PPV-M-infected trees has 
been done in these orchards. Such information can be of great importance in fully understanding disease distribution and dynamics (28), to develop more accurate sampling plans (31), and to develop and improve effective strategies of removal of diseased trees.

Analysis of the spatial pattern and spread of PPV in orchards is relatively rare and available only for orchards infected by the PPV-D strain $(10,15,34)$. Very recently, PPV-M spread has been monitored in apricot orchards in southern Greece, but the analysis was mainly focused on temporal aspects (51). The most recent extensive analysis was conducted on the spatial pattern of Sharka disease affecting apricot and peach orchards in Spain (10). Only a few orchard-by-year assessments were found to have aggregation of adjacent Sharka-diseased trees within and across the row directions. In addition, aggregation of disease incidence for data partitioned within contiguous quadrats from $2 \times 2$ to $3 \times 3$ trees was rare and more frequent for plots with higher disease incidence. Two-dimensional distance class and semivariance analyses confirmed a general lack of spatial dependency of immediately adjacent PPV-infected trees and showed a trend for higher-order spatial relationships for distances corresponding to approximately 4 to 7 and again at 9 to 15 trees away (10).

A variety of statistical tools are currently available to quantify spatial pattern of disease within plots $(28,30,50)$. Aggregation between adjacent trees in one direction (within or across rows) can be evaluated by the commonly used ordinary runs analysis (32). Distributional approaches like the beta-binomial distribution and the binary form of Taylor's power law can be used to evaluate heterogeneity in disease incidence for data grouped into sampling units (e.g., quadrats) and to assess the pattern of disease at some scale within the quadrats $(20,30)$. These approaches have been used to develop and adjust hierarchical sampling methods for the assessment of Citrus tristeza virus and PPV incidence throughout the Prunus production areas of the United States and Canada (17-19).

Spatial relationships among sampling units or quadrats with similar disease status can be generally evaluated by spatial autocorrelation $(14,46)$. The spatial analysis by distance indices (SADIE) method, developed to detect clusters in counts data independent of their numeric properties $(37,38,40)$, was recently used to quantify the spatial patterns of fungal and viral diseases $(22,38,44,47,49)$.

The objectives of this study were to examine the spatial patterns of PPV-M in peach orchards in southern France and to compare these patterns with those previously characterized for PPV-D elsewhere.

\section{MATERIALS AND METHODS}

Field plots and surveys. Eighteen peach orchards located in commercial stone fruit plantings in the Gard (G) and PyrénéesOrientales (PO) areas in southern France were surveyed for PPV infections. The two areas are located about $200 \mathrm{~km}$ apart. The peach cultivars, size of the plots, and density of planting are reported in Table 1. All plots were irrigated and received standard commercial horticultural, disease, and insect management.

Plots were surveyed visually for the presence of PPV symptoms by trained professional teams. The reliability of visual inspections to detect PPV infections on peach was assessed by comparing the results of visual inspections with those obtained from a fieldadapted immuno-printing detection test (25) performed on 1,000 individual trees (G. Labonne, unpublished data). All trees in each surveyed plot were inspected two to three times each year from spring to early summer when symptoms are most easily observed. Some plots were surveyed for a single year and destroyed when incidence exceeded established threshold PPV levels, whereas others were surveyed annually for up to three successive years. In the latter case, PPV-infected trees were identified and removed each year. Initial infection within each plot was confirmed via double-antibody sandwich enzyme-linked immunosorbent assay on a bulk sample of leaves collected from one to several symptomatic trees. The strain of PPV was characterized via polymerase chain reaction or western blot (2). All plots were infected exclusively with the PPV-M strain.

Collection and partitioning of the data. Maps with locations of all symptomatic and nonsymptomatic trees, a complete census of binary data, were prepared from survey results for each plot and each year. When disease was assessed for several years, annual maps recording all previous and new infections were available and cumulative infection data were analyzed. A total of 32 maps for the 18 plots were used for analysis. The binary data also were parsed into contiguous quadrats of various sizes $(2 \times 2,3 \times 3$, and $4 \times 4$ trees per quadrat). The resulting number of quadrats, $N$, per plot varied from 12 to 493 , depending on the plot and quadrat size.

Spatial analyses. The methods undertaken used the individual binary data directly for unidirectional analysis (ordinary runs) or when grouped into quadrats, allowing us to evaluate the spatial patterns of infected trees within the quadrats via the analysis of heterogeneity of disease incidence (point pattern analysis) as well as the spatial arrangements of the quadrats with infected trees (SADIE).

Ordinary runs. Ordinary runs analyses were performed on binary data from each plot and assessment date to determine if

TABLE 1. Characteristics of the peach plots in southern France surveyed for Plum pox virus (PPV) infections

\begin{tabular}{|c|c|c|c|c|c|c|}
\hline Location & Plot & Cultivar & Year of planting & Tree spacing $(\mathrm{m})$ & Number of trees & $\begin{array}{l}\text { Age at first PPV } \\
\text { detection (years) }\end{array}$ \\
\hline \multirow[t]{6}{*}{ Gard } & G-1 & Royal Glory & 1988 & $6 \times 2.6$ & 800 & 5 \\
\hline & G-2 & Spring Lady & 1987 & $6 \times 2.6$ & 831 & 6 \\
\hline & G-4 & $-^{\mathrm{a}}$ & 1980 & $4.5 \times 3.5$ & 650 & 14 \\
\hline & G-5 & August Red & 1990 & $5.5 \times 3$ & 448 & 4 \\
\hline & G-6 & Royal Glory & 1989 & $6 \times 2$ & 1,021 & 7 \\
\hline & G-7 & Red Top & 1978 & $5.5 \times 4.5$ & 528 & 15 \\
\hline Pyrénées & PO-1 & Flavor Giant & 1991 & $5 \times 2$ & 773 & 3 \\
\hline \multirow[t]{6}{*}{ Orientales } & PO-2 & O'Henry & 1992 & $5 \times 2.2$ & 1,994 & 1 \\
\hline & PO-3 & Gladys & 1989 & $5 \times 2$ & 734 & 3 \\
\hline & PO-4 & - & 1990 & $4 \times 2$ & 515 & 3 \\
\hline & PO-5 & Autumn Fruit & 1986 & $5 \times 3$ & 687 & 7 \\
\hline & PO-6 & Springcrest & 1991 & $4 \times 3.5$ & 247 & 3 \\
\hline & PO-7 & Opale & 1992 & $5 \times 2$ & 471 & 4 \\
\hline
\end{tabular}

\footnotetext{
${ }^{a}$ Unknown cultivar.
} 
aggregation existed between adjacent symptomatic trees within the row or across the rows with the use of a Visual Basic Excel macro (T. Gottwald, unpublished software). A nonrandom pattern (i.e., aggregation) of PPV symptomatic trees was assumed for each row separately if the observed number of runs was less than the expected number of runs at $P=0.05$ using a standard-normal test $(3,32)$.

Point pattern analysis. Heterogeneity in disease incidence can be evaluated by fitting the binomial and beta-binomial distributions to the frequency distribution of diseased plants per sampling unit or quadrat (21). The binomial distribution is the most appropriate to describe a random pattern of disease incidence, whereas the beta-binomial distribution suggests an aggregated pattern of disease incidence. Using the beta-binomial distribution software $(21,29)$, the maximum likelihood estimates and standard errors of the parameters $p$ (the expected probability of disease) and $\theta$ (a measure of the variation in disease incidence per quadrat) of the beta-binomial distribution were calculated for each plot and assessment date for the three quadrat sizes ( $n=4,9$, and 16 trees). $t$ tests were used to determine if the maximum likelihood estimates of $\theta$ differed significantly from 0 (when $\theta$ equals 0 , the beta-binomial distribution is reduced to the binomial distribution) (30). The $C(\alpha)$ test was used to test for the null hypothesis of randomness with the alternative hypothesis of overdispersion described specifically by the beta-binomial $(21,29)$. The test statistic has a standard-normal distribution under the null hypothesis of randomness and is given by $z_{\mathrm{C}(\alpha)}=[n(N-1) D-n N] /$ $\left[2 N\left(n^{2}-n\right)\right]^{1 / 2}$ (with $D$ defined as the ratio of the observed variance of diseased trees per sampling unit to the theoretical binomial variance).

Direct measurements of heterogeneity were provided by $\theta$ when the beta-binomial was appropriate (30). For some applications, it was reparameterized as the intracluster correlation coefficient $\rho=$ $\theta /(1+\theta)$, which is a measure of the tendency of individual plants within quadrats to have the same disease status when $n$ is not always constant $(30,33)$. We also calculated the index of dispersion $(D)$. Values of $D>1$ suggest aggregation because the observed variance of disease incidence is inflated above the expected binomial variance. The quantity $(N-1) D$ follows a $\chi^{2}$ distribution (with $N-1 \mathrm{df}$ ) under the null hypothesis of randomness.

The binary form of Taylor's power law was used as an assessment of overdispersion across all data sets and allowed us to examine if the degree of heterogeneity was related to the mean disease incidence. The power law modified by Hughes and Madden (20) for disease incidence data can be expressed as a relationship between the observed sample variance of diseased trees within quadrats $\left(v_{\mathrm{obs}}\right)$ and the theoretical variance of random distribution $\left(v_{\text {bin }}\right)$, that is the binomial variance for binary data $[n p(1-p)]$. It can be written as $\ln \left(v_{\text {obs }}\right)=\ln \left(A_{x}\right)+b \ln \left(v_{\text {bin }}\right)$, in which $\ln \left(A_{x}\right)$ and $b$ are the intercept and the slope of the regression line, respectively. When both $A_{x}$ and $b$ are equal to 1 , then a random spatial pattern is suggested and best described by the binomial distribution. When $b=1$ and $A_{x}>1$, there is overdispersion with no dependence on $p$. When both $A_{x}$ and $b$ are $>1$, the degree of aggregation varies with $p$. The parameters $\ln \left(A_{x}\right)$ and $b$ were estimated by linear regression using the leastsquares method. The equality of $\ln \left(A_{x}\right)$ to 0 and $b$ to 1 was tested by a $t$ test using the estimates of the parameter and its standard error.

SADIE. SADIE was used to evaluate the spatial arrangement of quadrats with infected trees at the plot scale. The method uses the coordinates (location) of the quadrats and the counts of individuals (i.e., symptomatic trees) per quadrat to quantify the spatial pattern in the sampled population $(37,38)$. This is done by measuring the minimum total effort that the individuals must expend to move to arrangements in which the individuals are spaced as regularly as possible (i.e., achieve the same number $m$ in each sampling unit). This effort is represented by the distance to regularity
$\left(D_{r}\right)$. The degree of nonrandomness within a set of data is quantified by comparing the observed spatial pattern with rearrangements obtained after random permutations of the individuals among the quadrats. $P_{a}$, defined as the proportion of randomized samples with distance to regularity as large as or larger than the observed value of $D_{r}$, can be used for a one-sided test of spatial aggregation (at the significance level of 5\%). The hypothesis of a more regular spatial distribution of counts than would be expected by chance could also be tested but was not of interest here because very few such arrangements occur in field data (22). An overall index of aggregation $\left(I_{a}\right)$ is given by $I_{a}=D_{r} / E_{a}$, where $E_{a}$ is equal to the mean distance to regularity of the randomized samples. An aggregated pattern is indicated by $I_{a}>1$, a spatially random pattern if $I_{a}=1$, and a regular pattern if $I_{a}<1$. The red-blue extension of SADIE was used to measure and map the degree of pattern locally (40). The organization of clusters into patches (neighborhoods of units with counts larger than the average density of $m$ ) or gaps (neighborhoods of units with counts of $<m$ ) can be analyzed by computing a dimensionless index of clustering from randomizations for each sampling unit (quadrat) (40). The index $v_{i}$ measures the degree to which the unit contributes to a patch, whereas $v_{j}$ is defined similarly but for a gap and takes by convention a negative value. As a general rule, we considered large values of $v_{i}>1.5$ or small values of $v_{j}<-1.5$ as members of a patch or a gap, respectively (1.5 the expected values of $v_{i}=1$ or $v_{j}=-1$ for random arrangements). A more formal test of the degree of clustering was provided by comparing the average values of $v_{i}$ and $v_{j}$ with their corresponding values from randomizations. Maps and contour plots were drawn from those values. The number of the patch and gap clusters, their location, and their size were analyzed visually and by using the information provided by the clusterxyc.exe program (described below).

TABLE 2. Ordinary runs analysis for Plum pox virus symptomatic trees in peach orchards of southern France

\begin{tabular}{|c|c|c|c|}
\hline \multirow[b]{2}{*}{ Plot } & \multirow[b]{2}{*}{ Year } & \multicolumn{2}{|c|}{ Row direction ${ }^{\mathrm{a}}$} \\
\hline & & Within & Across \\
\hline G-1 & 1993 & $11 / 11$ & $1 / 63$ \\
\hline G-2 & 1993 & $8 / 11$ & $3 / 56$ \\
\hline \multirow[t]{3}{*}{ G-3 } & 1993 & $0 / 11$ & $0 / 30$ \\
\hline & 1994 & $2 / 11$ & $0 / 30$ \\
\hline & 1995 & $2 / 11$ & $2 / 31$ \\
\hline \multirow[t]{3}{*}{ G-4 } & 1994 & $1 / 7$ & $0 / 8$ \\
\hline & 1995 & $1 / 12$ & $2 / 18$ \\
\hline & 1996 & $0 / 19$ & $1 / 27$ \\
\hline G-5 & 1994 & $3 / 13$ & $3 / 32$ \\
\hline G-6 & 1996 & $7 / 12$ & $5 / 71$ \\
\hline \multirow[t]{2}{*}{ G-7 } & 1993 & $3 / 16$ & $2 / 15$ \\
\hline & 1994 & $3 / 16$ & $2 / 25$ \\
\hline \multirow[t]{2}{*}{ G-8 } & 1993 & $0 / 13$ & $0 / 18$ \\
\hline & 1994 & $3 / 19$ & $2 / 25$ \\
\hline \multirow[t]{3}{*}{ G-9 } & 1993 & $0 / 8$ & $0 / 22$ \\
\hline & 1994 & $1 / 9$ & $0 / 29$ \\
\hline & 1995 & $0 / 9$ & $0 / 30$ \\
\hline \multirow[t]{3}{*}{ PO-1 } & 1994 & $2 / 10$ & $0 / 14$ \\
\hline & 1995 & $2 / 13$ & $0 / 18$ \\
\hline & 1996 & $2 / 16$ & $0 / 29$ \\
\hline PO-2 & 1993 & $9 / 29$ & $3 / 48$ \\
\hline \multirow[t]{3}{*}{ PO-3 } & 1992 & $2 / 12$ & $0 / 26$ \\
\hline & 1993 & $4 / 13$ & $0 / 47$ \\
\hline & 1994 & $4 / 13$ & $4 / 55$ \\
\hline PO-4 & 1993 & $4 / 14$ & $3 / 35$ \\
\hline PO-5 & 1993 & $5 / 11$ & $6 / 14$ \\
\hline PO-6 & 1994 & $5 / 13$ & $1 / 13$ \\
\hline \multirow[t]{2}{*}{ PO-7 } & 1996 & $3 / 12$ & $13 / 20$ \\
\hline & 1997 & $3 / 14$ & $12 / 20$ \\
\hline \multirow[t]{2}{*}{ PO-8 } & 1993 & $0 / 10$ & $0 / 25$ \\
\hline & 1994 & $1 / 12$ & $1 / 38$ \\
\hline PO-9 & 1999 & $8 / 12$ & $7 / 36$ \\
\hline
\end{tabular}

${ }^{a}$ Values correspond to the number of rows with significant aggregation $(P=$ $0.05)$ relative to the total number of rows tested. 
We performed SADIE and red-blue analyses for each plot parsed into quadrats of $2 \times 2$ trees. We used the recent version of SADIE (SADIEshell software, available at the Rothamsted Research Institute website) with the rbrelv13.exe and clusterxyc.exe programs developed by Perry et al. (40). A total of 2,028 randomizations were performed for each individual analysis. "Bubble" and contour plots were drawn using the Surfer 8 software (Golden Software, Golden, CO).

\section{RESULTS}

Aggregation of diseased trees within rows. Ordinary runs analysis provided a simple way to detect aggregation of adjacent symptomatic trees in a single direction at a specific time, within or across rows. All the plots showed aggregation of symptomatic trees at least within one or across one row at one assessment date (Table 2). However, the proportion of rows or across-rows with aggregated symptomatic trees was highly variable from one plot to another and was generally low. Aggregation involving more than $50 \%$ of the rows or across-rows was detected in only five plots, three from the Gard area and two from the Pyrénées Orientales area.

Heterogeneity of disease incidence. Distribution analysis and measures of aggregation. Because the number of disease classes often was too low to compute $\chi^{2}$ goodness-of-fit tests, the adequacy of the beta-binomial distribution to describe the frequency distribution of disease incidence in the plots studied was evaluated by the $C(\alpha)$ test and indirectly by testing the departure of the $\theta$ parameter from 0 . The likelihood estimates of the beta-binomial parameters $p$ and $\theta$ could be calculated in $77 \%$ of the data sets (all quadrat sizes included), and in $70.2 \%$ of these cases, $t$ tests showed that the value of $\theta$ was significantly different from 0 (Table 3). A very high agreement $(96 \%)$ was found between the results of the test of $\theta$ and the results of the $C(\alpha)$ test. However, the $\mathrm{C}(\alpha)$ test indicated nonrandomness more often (in $63.5 \%$ versus $53.1 \%$ of the whole data set), partly because the likelihood estimation of the beta-binomial parameter was not always possible. In this latter case, disease incidence often was less than 0.10 or the moment estimate of $\theta$ was close or equal to 0 . There was also a complete agreement between the results of the $\mathrm{C}(\alpha)$ test and the $\chi^{2}$ test for $D$.

Aggregation of disease incidence was indicated for at least one yearly assessment for the majority of plots from the Pyrénées Orientales area (in eight of nine plots) and for the Gard area (in seven of nine plots) (Table 3). Absence of aggregation for all quadrat sizes and for each year of the survey was observed for G3, G-9, and PO-8 plots, whereas aggregation for PO-1 appeared very transient. When significant heterogeneity was detected, it generally included all quadrat sizes from $2 \times 2$ to $4 \times 4$ trees, but its intensity varied among plots, with assessment dates and size of the quadrats. When the tests for aggregation were significant, estimated $\theta$ values ranged from 0.04 to 1.28 and $D$ values from 1.19 to 7.1 for all quadrat sizes. The index of dispersion $(D)$ generally increased with increasing quadrat size (median values of 1.46, 1.98, and 2.78 for quadrats of $2 \times 2,3 \times 3$, and $4 \times 4$ trees, respectively, for all data with significant aggregation). The $\theta$ parameter appeared globally more stable (median values of 0.17 , 0.15 , and 0.16 for quadrats of $2 \times 2,3 \times 3$, and $4 \times 4$ trees, respectively), even though individual plots showed distinct trends (Table 3).

TABLE 3. Heterogeneity of Sharka disease incidence in peach plots of southern France

\begin{tabular}{|c|c|c|c|c|c|c|c|c|}
\hline \multirow[b]{2}{*}{ Plot } & \multirow[b]{2}{*}{ Year } & \multirow[b]{2}{*}{ Disease incidence $(p)$} & \multicolumn{3}{|c|}{ Beta-binomial parameter $(\theta)^{\mathrm{a}}$} & \multicolumn{3}{|c|}{ Dispersion index $(D)^{\mathrm{b}}$} \\
\hline & & & Quadrat $2 \times 2$ & Quadrat $3 \times 3$ & Quadrat $4 \times 4$ & Quadrat $2 \times 2$ & Quadrat $3 \times 3$ & Quadrat $4 \times 4$ \\
\hline G-1 & 1993 & 0.3500 & $0.82 *$ & 0.86 & 0.93 & $2.19 *$ & $4.44 *$ & $7.1 *$ \\
\hline G-2 & 1993 & 0.1552 & $0.19 *$ & $0.23 *$ & $0.18 *$ & $1.46^{*}$ & $2.38 *$ & $3.28 *$ \\
\hline \multirow[t]{3}{*}{ G-3 } & 1993 & 0.1551 & 0.00 & 0.00 & 0.00 & 0.82 & 1.04 & 0.75 \\
\hline & 1994 & 0.1800 & 0.00 & 0.04 & 0.00 & 0.82 & 1.37 & 1.06 \\
\hline & 1995 & 0.2077 & 0.00 & 0.03 & 0.00 & 0.89 & 1.27 & 1.03 \\
\hline \multirow[t]{3}{*}{ G-4 } & 1994 & 0.0184 & 0.00 & 0.11 & 0.01 & 0.95 & $1.85 *$ & 1.13 \\
\hline & 1995 & 0.0440 & 0.03 & $0.09 *$ & $0.05^{*}$ & 1.08 & $1.75 *$ & $1.69 *$ \\
\hline & 1996 & 0.1569 & $0.08 *$ & $0.09 *$ & $0.06^{*}$ & $1.22 *$ & $1.64 *$ & $2.03 *$ \\
\hline G-5 & 1994 & 0.1763 & $0.18 *$ & $0.17 *$ & $0.16^{*}$ & $1.43 *$ & $2.31 *$ & $3.29 *$ \\
\hline G-6 & 1996 & 0.1586 & $0.18 *$ & $0.09 *$ & $0.08^{*}$ & $1.50 *$ & $1.73 *$ & $2.11 *$ \\
\hline \multirow[t]{2}{*}{ G-7 } & 1993 & 0.0530 & $0.17 *$ & $0.13 *$ & $0.09 *$ & $1.50 *$ & $1.98 *$ & $2.29 *$ \\
\hline & 1994 & 0.1079 & $0.10 *$ & $0.12 *$ & 0.04 & $1.34 *$ & $1.96^{*}$ & $1.61 *$ \\
\hline \multirow[t]{2}{*}{ G-8 } & 1993 & 0.0400 & 0.07 & 0.02 & 0.02 & $1.19 *$ & 1.15 & 1.36 \\
\hline & 1994 & 0.1038 & $0.08 *$ & $0.06 *$ & $0.05 *$ & $1.20 *$ & $1.42 *$ & $1.83 *$ \\
\hline \multirow[t]{3}{*}{ G-9 } & 1993 & 0.0588 & 0.00 & 0.00 & 0.04 & 0.96 & 0.99 & 1.35 \\
\hline & 1994 & 0.0828 & 0.00 & 0.00 & 0.01 & 0.91 & 0.81 & 1.26 \\
\hline & 1995 & 0.0899 & 0.00 & 0.00 & 0.02 & 0.93 & 0.93 & 1.37 \\
\hline \multirow[t]{3}{*}{ PO-1 } & 1994 & 0.0232 & 0.02 & 0.15 & 0.02 & 1.05 & $1.68 *$ & $1.37 *$ \\
\hline & 1995 & 0.0290 & 0.00 & 0.09 & 0.01 & 1.00 & 1.46 & 1.25 \\
\hline & 1996 & 0.0580 & 0.04 & $0.06 *$ & 0.02 & 1.10 & $1.46^{*}$ & 1.34 \\
\hline PO-2 & 1993 & 0.0602 & $0.13 *$ & $0.08 *$ & $0.06^{*}$ & $1.32 *$ & $1.60 *$ & $1.82 *$ \\
\hline \multirow[t]{3}{*}{ PO-3 } & 1992 & 0.0531 & $0.10 *$ & $0.08 *$ & $0.06^{*}$ & $1.29 *$ & $1.78 *$ & $1.63 *$ \\
\hline & 1993 & 0.1362 & $0.14 *$ & $0.08 *$ & $0.04 *$ & $1.40 *$ & $1.66 *$ & $1.66^{*}$ \\
\hline & 1994 & 0.2806 & $0.27 *$ & $0.17 *$ & $0.17 *$ & $1.66^{*}$ & $2.22 *$ & $3.34 *$ \\
\hline PO-4 & 1993 & 0.2019 & $0.16^{*}$ & $0.17 *$ & $0.17 *$ & $1.44 *$ & $2.41 *$ & $3.54 *$ \\
\hline PO-5 & 1993 & 0.0800 & $0.64 *$ & $0.66^{*}$ & 0.75 & $2.16^{*}$ & $4.24 *$ & $7.61 *$ \\
\hline PO-6 & 1994 & 0.1943 & $0.32 *$ & $0.40 *$ & $0.27 *$ & $1.75^{*}$ & $3.45 *$ & $4.14 *$ \\
\hline \multirow[t]{2}{*}{ PO-7 } & 1996 & 0.1783 & $1.28 *$ & $0.92 *$ & $0.66^{*}$ & $2.68 *$ & $4.84 *$ & $6.90 *$ \\
\hline & 1997 & 0.1911 & $1.10^{*}$ & $1.23 *$ & $0.95^{*}$ & $2.58 *$ & $4.72 *$ & $6.72 *$ \\
\hline \multirow[t]{2}{*}{ PO-8 } & 1993 & 0.0615 & 0.00 & 0.01 & 0.00 & 1.02 & 1.10 & 0.73 \\
\hline & 1994 & 0.1266 & 0.03 & 0.04 & 0.02 & 1.10 & 1.30 & 1.40 \\
\hline PO-9 & 1999 & 0.2395 & $0.53 *$ & $0.50 *$ & 0.46 & $2.06^{*}$ & $3.75 *$ & $5.93 *$ \\
\hline
\end{tabular}

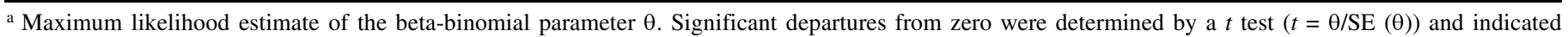
overdispersion. Significance $(*)$ is indicated at $P=0.05$. Values in italics indicate that the likelihood estimation procedure for the $p$ and $\theta$ parameters of the beta-binomial distribution failed to converge and that $\theta$ was calculated using the moment method, but its departure from zero could not be tested (29).

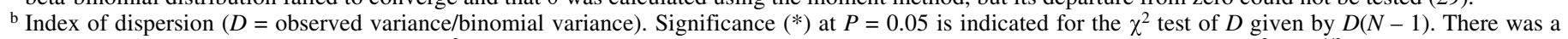
total agreement between the results of this $\chi^{2}$ test and the $\mathrm{C}(\alpha)$ test based also on $D$ and given by $z_{\mathrm{C}(\alpha)}=[(n N-1) D-n N] /\left[2 N\left(n^{2}-n\right)\right]^{1 / 2}$. 
Plotting the intracluster correlation coefficient $(\rho)$ (directly related to parameter $\theta$ ) against disease incidence suggested a positive relationship between aggregation and disease incidence, especially for quadrats of $2 \times 2$ trees. There was, however, considerable variation in the $\rho$ values at a given $p$ (Fig. 1A to C). A similar trend was observed with the dispersion index $(D)$ (data not shown).

Binary power law. The binary form of Taylor's power law provided a good description of the relationship between the loga- rithms of observed variance and binomial variance considering all plots concomitantly. Estimated slopes and intercepts were significantly $(P<0.001)$ greater than 1 and 0 for all quadrat sizes, respectively. This relation was better explained, however, with quadrats of 4 trees than with quadrats of 9 and 16 trees (Table 4). For all quadrat sizes, most of the points (each point representing one plot at one assessment date) were clearly located above the binomial (random) line (Fig. 1D to F). With both $A_{x}$ and $b>1$, the degree of heterogeneity varied with disease incidence.
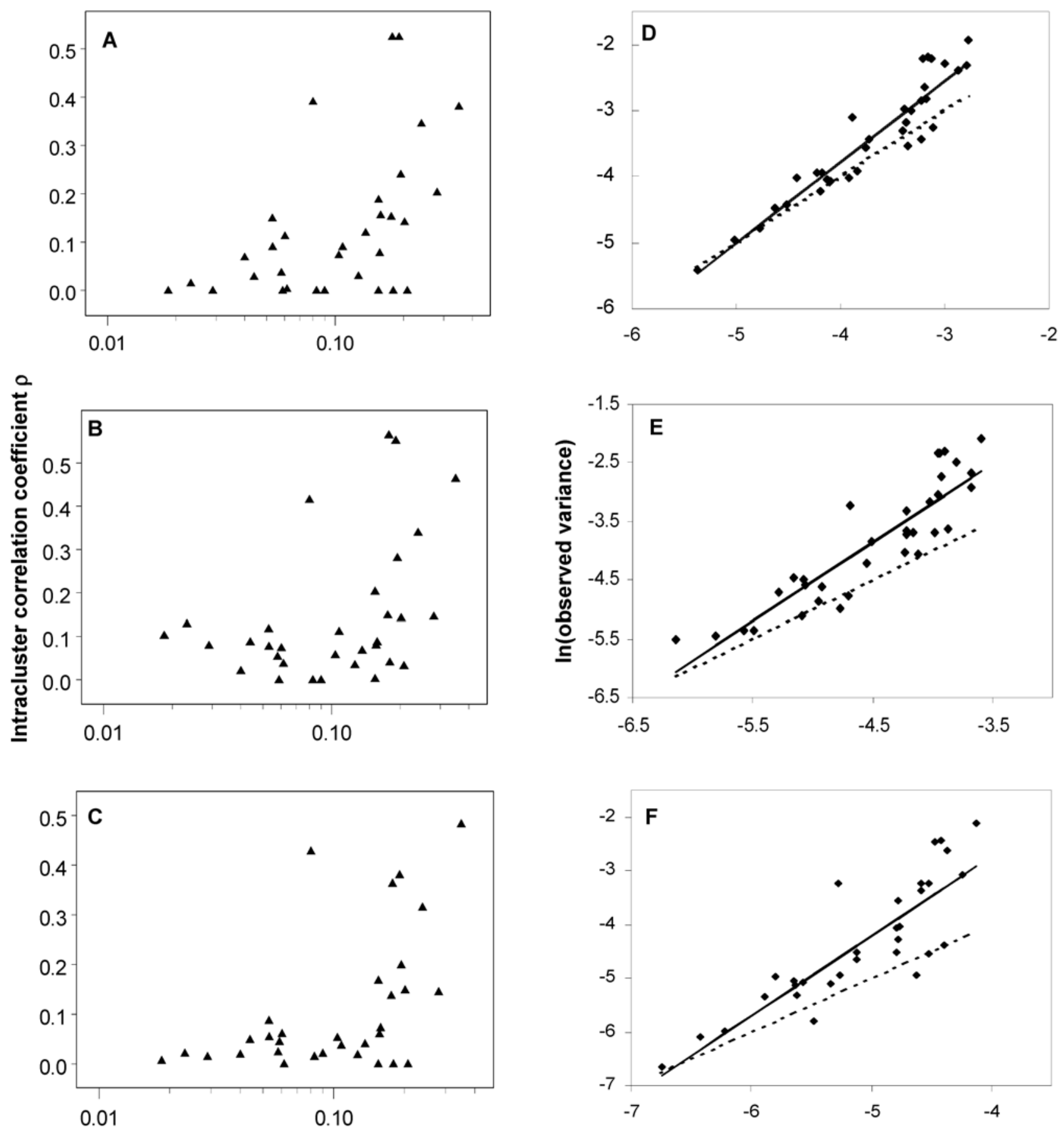

Disease incidence

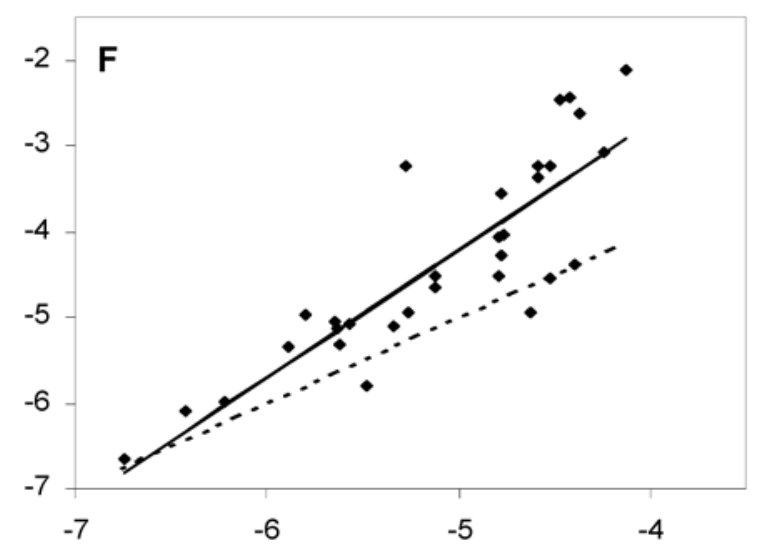

In(binomial variance)

Fig. 1. A to C, Relationship between the intracluster correlation coefficient and disease incidence. D to F, Binary Taylor's power law results, i.e., relationship between the observed variance and the theoretical binomial variance for incidence of Plum pox virus in peach plots of southern France. A and D, quadrats of $2 \times 2$ trees; $\mathbf{B}$ and $\mathbf{E}$, quadrats of $3 \times 3$ trees; and $\mathbf{C}$ and $\mathbf{F}$, quadrats of $4 \times 4$ trees. D to $\mathbf{F}$, The solid line represents the relationship between ln(observed variance) and $\ln ($ binomial variance) fitted to the data by least-squares regression. The dashed line represents the binomial line, $\ln ($ observed variance $)=$ $\ln$ (binomial variance). Each point represents an individual annual plot assessment. 
Spatial arrangement of quadrats with infected trees. The SADIE program successfully calculated the distance to regularity $\left(D_{r}\right)$ and the distribution of the distances to regularity under randomizations for all data sets. The index of aggregation $\left(I_{a}\right)$ and $P_{a}$, the

TABLE 4. Results of the binary power law analysis of the incidence of Plum pox virus in peach orchards of southern France at three quadrat sizes ${ }^{\mathrm{a}}$

\begin{tabular}{lcccc}
\hline Quadrat size & $b$ & $\ln \left(A_{x}\right)$ & df & $R^{2}$ \\
\hline $2 \times 2$ & $1.22(0.081)$ & $1.12(0.306)$ & 33 & 0.88 \\
$3 \times 3$ & $1.34(0.123)$ & $2.17(0.562)$ & 33 & 0.79 \\
$4 \times 4$ & $1.48(0.163)$ & $3.18(0.839)$ & 32 & 0.73
\end{tabular}

${ }^{a} b$ and $\ln \left(A_{x}\right)$ are the estimated slope and intercept, respectively, of the best fitting line based on least-squares regression. Numbers in parentheses correspond to standard errors. proportion of randomized samples larger than the observed value of $D_{r}$, indicated significant aggregation of quadrats with symptomatic trees for at least one assessment in six of the nine plots from the Gard area (Table 5) and in seven of the nine plots from the Pyrénées Orientales area (Table 6). Computation of the indices of clustering for patch $\left(v_{i}\right)$ and gaps $\left(v_{j}\right)$ verified these results in most cases. The $v_{i}$ and $v_{j}$ indices appeared more informative than the $I_{a}$ index alone for plots PO-1 (1996) and G-9 (1995), but in these cases, only one of the two clustering indices was significant. For plots PO-3 (1994) and G-6, significant clustering was indicated only for gaps even though $P$ values associated with patch clustering were very close to the $5 \%$ probability level. Further analysis using the maximum number of randomizations possible $(5,967)$ showed a decrease in $P$ values associated to patch clustering without, however, achieving significance (data not shown).

TABLE 5. Spatial analysis by distance indices (SADIE) of the incidence of Plum pox virus in peach orchards from the Gard area in southern France

\begin{tabular}{|c|c|c|c|c|c|c|c|c|c|c|c|}
\hline \multirow[b]{2}{*}{ Plot } & \multirow[b]{2}{*}{ Year } & \multicolumn{2}{|c|}{ Index of aggregation $^{a}$} & \multicolumn{4}{|c|}{ Indices of clustering ${ }^{b}$} & \multicolumn{2}{|c|}{ Patchiness $^{\mathrm{c}}$} & \multicolumn{2}{|c|}{$\begin{array}{l}\text { Distance from main } \\
\text { to secondary patch }\end{array}$} \\
\hline & & $I_{a}$ & $P_{a}$ & $\bar{v}_{i}$ & $P$ & $\bar{v}_{j}$ & $P$ & No. of patches & Size & $x$ distance & $y$ distance \\
\hline G-1 & 1993 & $7.225^{*}$ & $<0.0005$ & $6.719 *$ & 0.0000 & $-7.585^{*}$ & 0.0000 & 1 & 47 & NA & NA \\
\hline G-2 & 1993 & $5.817 *$ & $<0.0005$ & $5.940 *$ & 0.0000 & $-5.880 *$ & 0.0000 & 7 & $42(2,3,5)$ & 1.68 & 8.21 \\
\hline \multirow[t]{3}{*}{ G-3 } & 1993 & 0.772 & 0.9453 & 0.745 & 0.9692 & -0.723 & 0.9880 & - & - & - & - \\
\hline & 1994 & 1.016 & 0.3521 & 0.999 & 0.3915 & -0.995 & 0.4068 & - & - & - & - \\
\hline & 1995 & 1.276 & 0.1487 & 1.283 & 0.1179 & -1.249 & 0.1453 & - & - & - & - \\
\hline \multirow[t]{3}{*}{$\mathrm{G}-4$} & 1994 & 1.223 & 0.0947 & 1.252 & 0.0754 & -1.234 & 0.0853 & - & - & - & - \\
\hline & 1995 & $1.713^{*}$ & $<0.0005$ & $1.713^{*}$ & 0.0010 & $-1.713 *$ & 0.0010 & 3 & $8(2,3)$ & 1.71 & 5 \\
\hline & 1996 & $1.749 *$ & $<0.0005$ & $1.554 *$ & 0.0085 & $-1.751 *$ & 0.0000 & 3 & $30(2)$ & $5(0.5)$ & $2.8(4.69)$ \\
\hline G-5 & 1994 & 1.329 & 0.0923 & 1.207 & 0.1333 & -1.360 & 0.0803 & - & - & - & - \\
\hline G-6 & 1996 & $1.746^{*}$ & 0.0330 & 1.553 & 0.0572 & $-1.699 *$ & 0.0340 & 7 & $11(2,5,7)$ & 0.8 & 6.41 \\
\hline \multirow[t]{2}{*}{ G-7 } & 1993 & $1.797^{*}$ & $<0.0005$ & $1.605^{*}$ & 0.0154 & $-1.797 *$ & 0.0051 & 2 & $4(2)$ & 4 & 2.5 \\
\hline & 1994 & $1.589 *$ & 0.0163 & $1.477 *$ & 0.0178 & $-1.581 *$ & 0.0108 & 3 & $7(2,3)$ & 1.33 & 9.38 \\
\hline \multirow[t]{2}{*}{ G-8 } & 1993 & $1.411^{*}$ & 0.0301 & $1.407 *$ & 0.0330 & $-1.411 *$ & 0.0321 & 1 & 5 & NA & NA \\
\hline & 1994 & $2.499 *$ & $<0.0005$ & $2.406^{*}$ & 0.0000 & $-2.480 *$ & 0.0000 & 6 & $15(2,3,6)$ & 0.40 & 5.06 \\
\hline \multirow[t]{2}{*}{ G-9 } & 1993 & 1.183 & 0.2103 & 1.377 & 0.1138 & -1.144 & 0.2559 & - & - & - & - \\
\hline & 1995 & 1.551 & 0.0636 & $1.727 *$ & 0.0316 & -1.462 & 0.0803 & 3 & $6(2,3)$ & 0.33 & 4.00 \\
\hline
\end{tabular}

${ }^{a} I_{a}$ is the overall index of aggregation and $P_{a}$ is the proportion of the 2,028 randomizations larger than $D_{r}$ (the moves to regularity of the observed data). The null hypothesis of spatial randomness is rejected if $P_{a}<0.05$ in favor of the alternative hypothesis of aggregation.

b $\bar{v}_{i}$ and $\bar{v}_{j}$ correspond to the average values of the indices of clustering $v_{i}$ (patch) and $v_{j}$ (gap) computed for each quadrat, respectively. $P$ values correspond to the proportion of randomized $\bar{v}_{i}$ or $\bar{v}_{j}$ that exceed the observed values.

${ }^{c}$ Patchiness indicates the number of patch clusters covering two or more quadrats with clustering indices greater than or equal to 1.5 as well as the size of the largest patch (the sizes for smaller ones are in parentheses). Information is given only for plots with significant overall aggregation and/or patch clustering.

$\mathrm{d}$ The distance between the centroid of the main patch cluster to the centroid of the secondary main patch cluster in quadrat units. When several clusters of the same size were observed, the distance was calculated in consideration of the most distant one.

TABLE 6. Spatial analysis by distance indices (SADIE) of the incidence of Plum pox virus in peach orchards from the Pyrénées Orientales area in southern France

\begin{tabular}{|c|c|c|c|c|c|c|c|c|c|c|c|}
\hline \multirow[b]{2}{*}{ Plot } & \multirow[b]{2}{*}{ Year } & \multicolumn{2}{|c|}{ Index of aggregation ${ }^{\mathrm{a}}$} & \multicolumn{4}{|c|}{ Indices of clustering ${ }^{\mathrm{b}}$} & \multicolumn{2}{|c|}{ Patchiness $^{\mathrm{c}}$} & \multicolumn{2}{|c|}{$\begin{array}{l}\text { Distance from main to } \\
\text { secondary patch }^{\mathrm{d}}\end{array}$} \\
\hline & & $I_{a}$ & $P_{a}$ & $v_{i}$ & $P$ & $v_{j}$ & $P$ & No. of patches & Size & $x$ distance & $y$ distance \\
\hline PO-1 & 1995 & 1.050 & 0.3128 & 1.051 & 0.2838 & -1.056 & 0.2923 & - & - & - & - \\
\hline PO-2 & 1993 & $1.961 *$ & $<0.0005$ & $1.813^{*}$ & 0.0000 & $-1.950 *$ & 0.0000 & 13 & $9(2,3,4)$ & 2.83 & 10.55 \\
\hline \multirow[t]{2}{*}{$\mathrm{PO}-3$} & 1992 & 0.945 & 0.4752 & 0.986 & 0.4085 & 0.952 & 0.4530 & - & - & - & - \\
\hline & 1993 & 1.125 & 0.2704 & 1.044 & 0.3007 & -1.165 & 0.1935 & - & - & - & - \\
\hline PO-6 & 1994 & $1.653^{*}$ & 0.0059 & $1.636^{*}$ & 0.0039 & $-1.686^{*}$ & 0.0025 & 1 & 14 & NA & NA \\
\hline \multirow[t]{2}{*}{ PO-7 } & 1996 & $2.757 *$ & $<0.0005$ & $2.503^{*}$ & 0.0000 & $-2.761 *$ & 0.0000 & 2 & $20(2)$ & 0.85 & 4.95 \\
\hline & 1997 & $2.792 *$ & $<0.0005$ & $2.525^{*}$ & 0.0000 & $-2.801 *$ & 0.0000 & 1 & 27 & NA & NA \\
\hline \multirow[t]{2}{*}{ PO-8 } & 1993 & 0.867 & 0.6222 & 0.848 & 0.7009 & -0.894 & 0.6017 & - & - & - & - \\
\hline & 1994 & 1.185 & 0.2120 & 1.204 & 0.1778 & -1.237 & 0.1538 & - & - & - & - \\
\hline PO-9 & 1999 & $4.734 *$ & $<0.0005$ & $2.806^{*}$ & 0.0000 & $-4.828^{*}$ & 0.0000 & 3 & $26(2)$ & 2.12 & 13.58 \\
\hline
\end{tabular}

${ }^{a} I_{a}$ is the overall index of aggregation and $P_{a}$ is the proportion of the 2,028 randomizations larger than $D_{r}$ (the moves to regularity of the observed data). The null hypothesis of spatial randomness is rejected if $P_{a}<0.05$ in favor of the alternative hypothesis of aggregation.

$\mathrm{b} \bar{v}_{i}$ and $\bar{v}_{j}$ correspond to the average values of the indices of clustering $v_{i}$ (patch) and $v_{j}$ (gap) computed for each quadrat, respectively. $P$ values correspond to the proportion of randomized $\bar{v}_{i}$ or $\bar{v}_{j}$ that exceed the observed values.

${ }^{c}$ Patchiness indicates the number of patch clusters covering two or more quadrats with clustering indices greater than or equal to 1.5 as well as the size of the largest patch (the sizes for smaller ones are in parentheses). Information is given only for plots with significant overall aggregation and/or patch clustering.

d The distance between the centroid of the main patch cluster to the centroid of the secondary main patch cluster in quadrat units. When several clusters of the same size were observed, the distance was calculated in consideration of the most distant one. 
A high heterogeneity of spatial patterns was suggested among the different plots when the maps of clustering indices were inspected (Fig. 2, example for plot G-4). One to thirteen distinct patches of infection (of two or more quadrats) per plot were visually identified in the plots for which overall aggregation was significant (Tables 5 and 6). There was often a large patch cluster and one to several smaller ones. The size of the larger patch clusters varied from 4 (G-7) to 47 (G-1) quadrats and often extended in the row direction, and several of them, especially in the Pyrénées Orientales region, shared a boundary with one edge of the plot. The secondary patch clusters were generally much smaller, extending from 2 to 11 quadrats (median size of three quadrats, i.e., 12 trees). They were located up to $90 \mathrm{~m}$ (for plot PO-9) from the main clusters, preferentially in the direction of the rows. When several time assessments were available for a plot, $I_{a}$ and $v_{i}$ values tended to increase, suggesting an intensification of clustering from 1 year to another. This was illustrated by a general increasing size of the main patch clusters as well.

The strongest clustering was detected in plots G-1 and G-2, located in the Gard region, as indicated by high significant values of aggregation and clustering indices ( $v_{i}$ values of 6.719 and 5.940 for G-1 and G-2, respectively). Such clustering was essentially related to a strong contrast between very large patches of infection constituted by 47 (G-1) and 42 (G-2) quadrats located at one extremity of the plot and large sparsely infected regions at the other extremity and with no (G-1 plot) or a limited number of small secondary clusters. In order to further characterize the organization of such patches, we reapplied SADIE to a smaller subset of data delimitated by the dimensions of these patches $(5 \times$ 13 quadrats for G-1 and $5 \times 11$ quadrats for G-2). Significant clustering $\left(v_{i}=1.6 .76\right.$ and $P=0.0146$ for G-1; $v_{i}=1.71$ and $P=$ 0.0082 for G-2) was still detected in these reduced areas but was much less intense; a unique patch cluster of 22 quadrats was still detected in the subarea of G-1, whereas the G-2 subarea enclosed four distinct patch clusters ranging from two to five quadrats in size (data not shown). This overall highly aggregated pattern contrasted with the spatial patterns observed in the other plots of the same region, for which clustering was less intense or nonsignificant ( $I_{a}$ ranging from 0.77 to 2.49 and $v_{i}$ from 0.74 to 2.4 ).

The spatial patterns appeared more homogeneous among the plots of the Pyrénées Orientales region in which overall aggregation was significant. In six of the seven plots, large patches encompassing 14 to 35 quadrats were detected as well as a limited number of secondary patch clusters (Table 6). When SADIE was reapplied on smaller subsets focusing on these large patches, clustering was still detected and was characterized by smaller patch clusters, with the exception of plot PO-7 in which the pattern was more homogeneous (data not shown). Only one plot (PO-2) revealed a more complex significantly clustered spatial pattern with numerous patches, ranging from two to nine quadrats in size.

\section{DISCUSSION}

Spatial pattern analysis of peach trees infected by PPV-M was undertaken in various peach orchards of southern France. To our knowledge, this study constitutes the first precise characterization of the spatial pattern of this aggressive strain in peach orchards. A wide range of patterns was detected, from no aggregation to very high aggregation of symptomatic trees, suggesting that aphid transmission of the virus to neighboring trees occurred frequently but was not systematic. The ecological conditions occurring in a particular orchard probably had a major influence on the resulting spread of the disease.

In France, when infections related to the PPV-M strain are discovered, removal of symptomatic peach trees is mandatory, and the entire orchard block is removed when disease incidence exceeds 10 to $20 \%$. Most of the plots presented in this study were
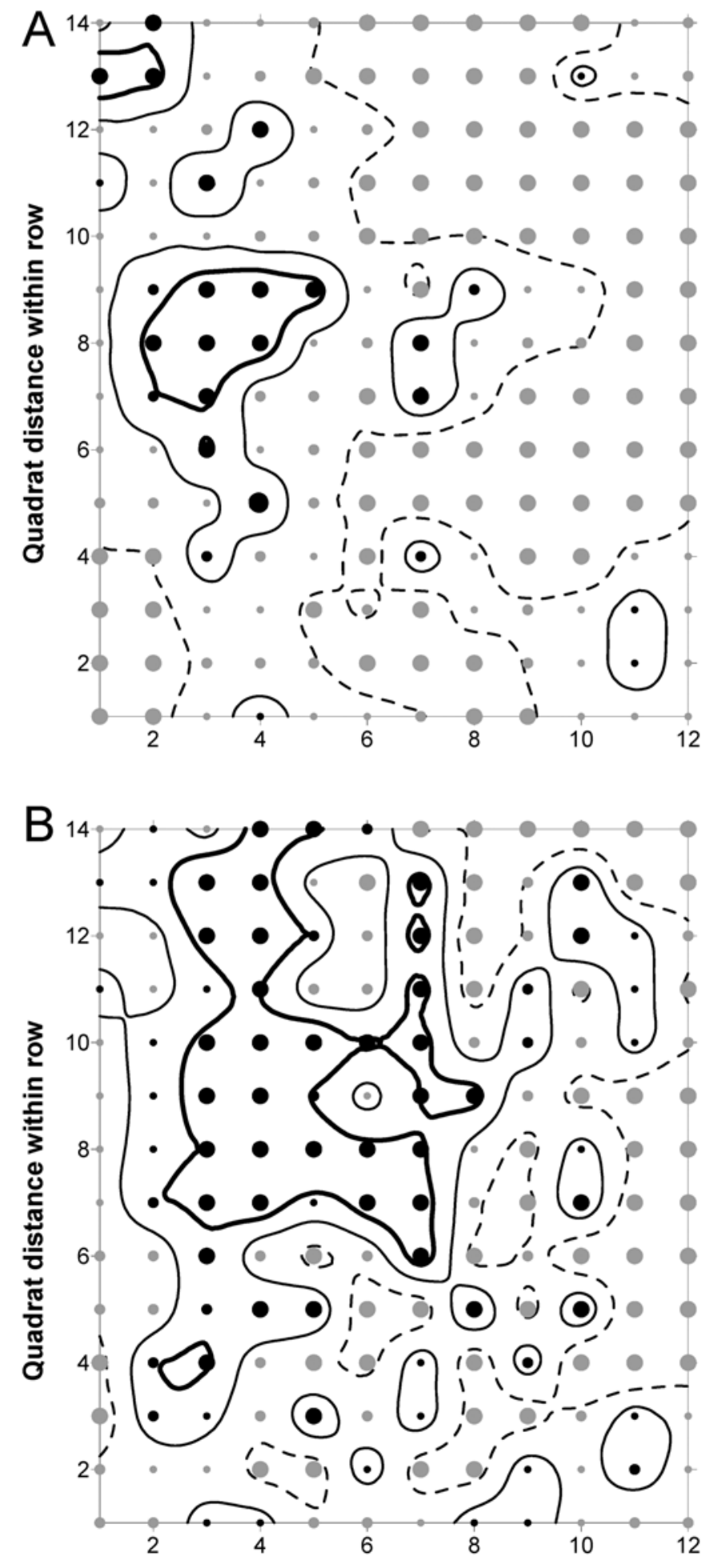

\section{Quadrat distance across row}

Fig. 2. Map of clustering indices computed with the spatial analysis by distance indices (SADIEshell) software for plot G-4 for cumulative numbers of symptomatic trees in A, 1995 and B, 1996. Axes show distances in quadrats of $2 \times 2$ trees with $y$ axis in the direction of rows of trees. Small black dots represent values of clustering indices $v_{i}$ of 0 to 0.99 (clustering below expectation), medium black dots are used for $1<v_{i}<1.49$ (slightly above expectation), and large black dots for $v_{i}>1.5$. The absolute values of $v_{j}$ are categorized similarly but in gray. Areas within contours with a value greater than 1.5 (thick solid line) indicate strong clustering as patches, those within contours of -1.5 indicate strong clustering as gaps (dashed line). The zero-value contours represent the interpolated boundary between patch and gap regions and are indicated by a thin solid line. 
discovered during the first years of the PPV-M epidemics in southern France (i.e., end of the 1980s and the beginning of the 1990s), when surveys were not systematic over large areas of production. For this reason, the discovery of the disease in some of these plots may have occurred several years after its introduction and disease incidence was already relatively high. Thus, a multiyear study of the spread of the disease was not always possible due to the immediate destruction of the plots when the disease incidence triggered eradication procedures.

Various point pattern and correlation-type methods were used to describe and analyze the spatial patterns of symptomatic trees, each of them bringing unique insights at some specific spatial scale. As previously pointed out by others $(39,42,49)$, the results of each approach can be combined in order to get a more comprehensive picture of the spatial patterns occurring in the plots studied. Indeed, information concerning the spatial relationship of adjacent PPV-infected trees could be inferred from ordinary runs and from the analyses of heterogeneity of disease incidence for the data grouped into quadrats; high heterogeneity of disease incidence indicating high similarity of disease status within the quadrats (49). SADIE and its red-blue extension were used to investigate spatial patterns at a larger scale, i.e., spatial arrangement of quadrats with infected trees. With our PPV data sets, results from SADIE were in very good agreement with those obtained from spatial autocorrelation (data not shown). Because SADIE was specifically designed to detect clusters in the form of patches or gaps independently of the numeric properties of the data, it was sensitive enough to detect patterns even when disease incidence was low (approximately 5\%) or when only loose clusters of symptomatic trees occurred. On the other hand, when there was a very strong contrast between large patches and gap clusters (e.g., plots G-1, G-2, and PO-4), reapplying SADIE to a smaller subset of data was useful to establish differences that were not apparent at a larger scale (7).

Influence of an infected tree on the disease status of its neighbors and local area of spread. Results from the ordinary runs and heterogeneity analyses of disease incidence were generally in good agreement, evidenced by a linear relationship between the proportion of rows with aggregation of infected trees (within-row orientation) and the values of both the beta-binomial $\theta$ parameter and dispersion index $(D)$ (data not shown). Ordinary runs indicated less aggregation across rows, but the smaller number of plants in this orientation likely had a strong influence on the power of the test. Based on the values of $\theta, \rho$, and $D$, a variety of patterns were evidenced among the plots tested, from no heterogeneity to very high heterogeneity of disease incidence. However, aggregation was clearly detected in a majority of plots (15 of 18) for at least one assessment and for all quadrat sizes from $2 \times 2$ to $4 \times 4$ trees. This result suggested that PPV-infected trees often influenced the PPV status of their adjacent neighbors, within areas circumscribed by at least 16 trees (larger quadrat size tested).

SADIE confirmed that clustering of symptomatic trees extended beyond the limits of the quadrats of $2 \times 2$ trees in 14 of the plots studied. Despite the variability of patterns found among the plots, ellipsoidal patch clusters extending in the row direction, from 4 to 14 trees within rows and 2 to 10 trees across rows, were often detected in the plots. Such clusters of infected trees can be interpreted as local areas of influence of PPV spread and are consistent with what is commonly observed with nonpersistent plant viruses, in which virus spread tends to be localized around primary foci of infection (48). The very large patches observed in some plots of both Gard and Pyrénées-Orientales areas (e.g., G-1, G-2, PO-4, and PO-7) might reflect a different situation. The incidence of the disease was generally higher in these plots, and multiple local clusters of infection might have coalesced previously to form much larger and dense areas of infection in the plots, as was the case for G-1 and PO-7. Indeed, strong $\theta$ and $D$ values indicated a very high similarity of disease within quadrats, and SADIE reapplied specifically to these areas of infection demonstrated a more homogeneous pattern. In contrast, the large patches observed for G-2 or PO-4 plots were more heterogeneous when SADIE was reapplied to a smaller data set; clustering was still detected in these areas characterized by several smaller patch clusters, and point pattern analysis suggested that aggregation of symptomatic trees within quadrats was less intense.

Despite the low number of assessments through time available for the same plots, the dynamics of aggregation related to increasing disease incidence was demonstrable at all spatial scales from both the analyses of heterogeneity of disease incidence and SADIE. The relationship between aggregation and disease incidence was not clearly seen at first by examining $\theta$ and $D$ values due to the high variability among the plots and also because only a very low number of plots were surveyed for several years. In these cases, the increase in disease incidence might have been stabilized somewhat because of the removal of symptomatic trees. However, when all the plots were considered concomitantly, the binary form of Taylor's power law clearly demonstrated that the degree of aggregation was a function of disease incidence for all quadrat sizes tested. This increasing clustering with time was also shown by SADIE by increasing values of clustering indices as well as patch cluster sizes.

Such aggregation of PPV-infected trees in relation with disease incidence suggests a vector transmission among neighboring plants from internal sources, in accordance with the polycyclic nature of the Sharka epidemic. New PPV infections occurring in the immediate proximity of previously infected trees have been observed in France in apricot orchards infected by the PPV-D strain (34), but this does not appear to occur frequently in the PPV epidemics in the United States (15) and was not observed in older peach and apricot orchards in Spain (10). In Spanish orchards, secondary spread of the disease by viruliferous aphids several trees away rather than to the immediately adjacent trees was suggested. One of the explanations proposed was that the spread of the disease was probably due to a migratory vector species rather than to a species colonizing Prunus crops (such as Myzus persicae Sulzer). Indeed, differences in the spatial patterns of spread of a semipersistent virus (Citrus tristeza virus) have been attributed to the presence/absence of colonizing versus migratory aphid species in citrus orchards (11-13). Noncolonizing species, i.e., potentially migratory species such as Aphis gossypii Glover and A. spiraecola Patch, both efficient vectors of PPV, have been found to be abundant in apricot orchards of the Mediterranean region $(1,23,26)$. Unpublished data suggest that no major differences exist in the diversity of aphid species visiting apricot versus peach orchards in the South of France (G. Labonne, unpublished data). Thus, the aggregated pattern of infected trees observed in this study cannot be linked to the flight behavior of a specific aphid vector species.

Longer-distance relationships between clusters of infected trees. Relationships between clusters of diseased trees at longer distances also were evidenced by SADIE. A large patch cluster and one to several smaller ones were detected in the majority of plots. These secondary clusters were preferentially oriented in the row direction up to $90 \mathrm{~m}$ from the main patch. Very few clusters were oriented in the across-row direction. However, the elongated rectangular shape of some of the plots tested may have hampered the detection of across-row associations. The occurrence of such smaller clusters can be interpreted as resulting from a secondary spread of the disease over longer distances from the largest focus, but can also represent later introductions from sources of inoculum outside the plots by more mobile vectors. In any case, shorterdistance vector transmissions occurred later in the epidemics, producing clusters of infected trees large enough to be detected by SADIE. In addition to these clusters, a number of infected trees, isolated or in groups of two to four, occurred in these plots but could not be detected by SADIE, which is not designed for this purpose. 
Variability of spatial patterns among PPV-M-infected plots. A variety of spatial patterns emerged when plots were compared with each other. An aggregated disease pattern, more or less intense depending on the plot, was observed at all spatial scales investigated in 14 of the 18 plots studied. Random disease patterns were much more likely to occur in the remaining four plots (G-3, G-9, PO-1, and PO-8). However, there was not a complete lack of pattern in two of the plots (G-9 and probably PO-1) as evidenced by SADIE with the detection of a few very loosely aggregated clusters of infected trees. Because virus incidence in these two plots was still low (less than 0.1), the eventual development of some aggregation cannot be ruled out. In contrast, disease incidence was much higher in plot G-3 $(p=0.21)$, and symptomatic trees were clearly scattered over all the plot dimensions.

One reason for such variability among the plots is probably due to the fact that the disease was often discovered several years after its introduction in the plots and the variable disease incidence at discovery blurred the initial spatial pattern to some extent. The mechanisms by which disease became established in the plots and the ecological conditions occurring in a particular orchard also appeared to have a major influence on the resulting pattern of disease through time.

Disease introduction in the plots may have been related to immigrant viruliferous aphids coming from external sources of infection or, in some cases, to the use of contaminated planting material. The latter mechanism is less likely to have occurred in more recent plantings because of the application of strict programs of certification of virus-free plant material and rules for the isolation of nurseries from commercial orchards. However, both mechanisms of disease introduction can result in very low incidence, random distributions of PPV-infected trees, or occasionally in higher incidence and more aggregated distributions that may impact on the future development of spatial patterns of the disease (48). The influence of strong external sources of infections was clearly exemplified with plots G-1 and G-2, in which large patches of infection sharing a long boundary with one edge of the plots were detected and disease gradients were observed. Severely infected peach orchards, located upwind and contiguous to these plots, most likely acted as strong sources of inoculum, inducing a dense deposition of viruliferous aphids at one end of G-1 and G-2 plots. Similar mechanisms probably occurred in several plots from the Pyrénées-Orientales area (especially PO-4 and PO-7) for which the spatial patterns of disease were comparable to those found for plots G-1 and G-2. In contrast, introductions of contaminated plant material in a strong grouping were most likely to have occurred in plot PO-5, for which a very highly aggregated spatial pattern was detected despite the low disease incidence in the plot and the lack of known sources of inoculum in the proximity.

Despite the potential impact of such disease introductions in some of the plots, the resulting spatial patterns appeared to be mainly associated with secondary spread of the disease via aphid vectors. Short-distance transmissions were clearly suggested in this study. Longer aphid transmissions likely occurred as well, in combination with shorter ones or as a dominant process, especially in the plots for which a random pattern of disease was identified. Numerous colonizing and migratory aphid species are able to transmit PPV and are found in the Prunus-growing regions of southern France (26). Thus, it is unlikely that only one species is responsible for the spatial patterns that develop through time in the plots analyzed (26). Numerous other factors may also modify aphid flight behavior and thus the resulting spatial patterns of infected peach trees, even within the same production area. The physical structure of an orchard affects wind flow in and above the orchard canopy and may thus influence the active flight of the vectors (24). The age of the trees, the density of planting, and the level of canopy opening varied among the plots analyzed (Table 1) and likely affected the resulting variability of spatial patterns of the disease even if the specific role of these factors could not be identified.

The spatial patterns of Sharka disease related to the PPV-M strain observed in this study do not appear to be specific to this particular strain. Previous studies have shown that PPV-D infections also may result in aggregated patterns in both apricot and plum orchards in France and Italy $(16,34)$, whereas in other studies of the same Prunus spp. and those including peach orchards resulted in very weak or no aggregation at all $(10,15)$. A recent but limited study of PPV-M spread in apricot orchards in Greece also suggested that the nearby ecological conditions had a strong impact on the variable spatial patterns of the disease observed in the orchards (51).

The frequent occurrence of clusters of infected trees observed in the majority of the peach orchards of this study has implications relative to control of the disease. Because surveys in France rely on visual inspections, latent infections are missed. Such latently infected trees, however, can play a significant role in disease spread, especially in early spring before inspections and removals start. To counteract such events, earlier inspection cycles have been implemented during the last few years in the South of France, relying on symptoms expressed in flowers in early spring. Taking into account the information revealed in this study, a better control probably could be achieved by also removing asymptomatic trees in the proximity of the symptomatic ones. A study of the dynamics of PPV spread over a longer period of time, especially in the current conditions of removal of symptomatic trees, would help to more accurately assess the impact of such measures.

\section{ACKNOWLEDGMENTS}

We thank the Féderation Régionale de Défense contre les Organismes Nuisibles (FREDON) of Provence Alpes Cote-d'Azur (PACA) and Languedoc-Roussillon (LR), their sections of Gard and PyrénéesOrientales, and the Service Régional de la Protection des Végétaux PACA and LR for the collection of data and their help in the selection of plots of interest, and the U.S. Department of Agriculture APHIS-PPQ for financial support.

\section{LITERATURE CITED}

1. Avinent, L., Hermoso de Mendoza, A., and Llácer, G. 1993. Comparison of sampling methods to evaluate aphid populations (Homoptera, Aphinidea) alighting on apricot trees. Agronomie 13:609-613.

2. Bousalem, M., Candresse, T., Quiot-Douine, L., and Quiot, J. B. 1994. Comparison of three methods for assessing Plum pox virus variability: Further evidence for the existence of two major groups of isolates. J. Phytopathol. 142:163-172.

3. Campbell, C. L., and Madden, L. V. 1990. Introduction to Plant Disease Epidemiology. John Wiley \& Sons, New York.

4. Crescenzi, A., d'Aquino, L., Comes, S., Nuzzaci, M., Piazzolla, P., Boscia, D., and Hadidi, A. 1997. Characterization of the sweet cherry isolate of Plum pox virus. Plant Dis. 81:711-714.

5. Dallot, S., Bousalem, M., Boeglin, M., Renaud, L. Y., and Quiot, J. B. 1997. Potential role of almond in Sharka epidemics: Susceptibility under controlled conditions to the main types of Plum pox potyvirus and survey for natural infections in South of France. EPPO Bull. 27:539-546.

6. Dallot, S., Labonne, G., Quiot-douine, L., Boeglin, M., Candresse, T., and Quiot, J. B. 1998. Peculiar Plum pox potyvirus D-populations are epidemic in peach trees. Acta Hortic. 472:355-365.

7. Dungan, J. L., Perry, J. N., Dale, M. R. T., Citron-Pousty, S., Fortin, M. J., Jakomulska, A., Legendre, P., Miriti, M., and Rosenberg, M. 2002. A balanced view of scaling in spatial statistical analysis. Ecography 25:626-640.

8. Festic, H. 1978. Investigation of new Sharka in apricot trees. Acta Hortic. 74:233-240.

9. Glasa, M., Marie-Jeanne, V., Labonne, G., Subr, Z., Kudela, O., and Quiot, J. B. 2002. A natural population of recombinant Plum pox virus is viable and competitive under field conditions. Eur. J. Plant Pathol. 108:843-853.

10. Gottwald, T. R., Avinent, L., Llacer, G., Hermoso de Mendosa, A., and Cambra, M. 1995. Analysis of the spatial spread of Sharka (Plum pox virus) in apricot and peach orchards in eastern Spain. Plant Dis. 79: 266-278. 
11. Gottwald, T. R., Cambra, M., Moreno, P., Camarasa, E., and Piquer, J. 1996. Spatial and temporal analyses of Citrus tristeza in eastern Spain. Phytopathology 86:45-55.

12. Gottwald, T. R., Garnsey, S. M., and Borbón, J. 1998. Increase and patterns of spread of Citrus tristeza virus infections in Costa Rica and the Dominican Republic in the presence of the brown citrus aphid, Toxoptera citricida. Phytopathology 88:621-636.

13. Gottwald, T. R., Gibson, G., Garnsey, S. M., and Irey, M. 1999. Examination of the effect of aphid vector population composition on the spatial dynamics of Citrus tristeza virus spread via stochastic modeling. Phytopathology 89:603-608.

14. Gottwald, T. R., Richie, S. M., and Campbell, C. L. 1992. LCOR2Spatial correlation analysis software for the personal computer. Plant Dis. 76:213-215.

15. Gottwald, T. R., Welliver, R., and Levy, L. 2001. Spatial pattern analyses of Plum pox virus in Pennsylvania. (Abstr.) Phytopathology 91(suppl.): S32.

16. Grzyb, Z. S. 1984. Spread of the Plum pox virus in the Italian plum orchard. Fruit Sci. Rep. 11:155-158.

17. Hughes, G., and Gottwald, T. R. 1998. Survey strategies for Citrus tristeza virus disease assessment. Phytopathology 88:715-723.

18. Hughes, G., and Gottwald, T. R. 1999. Survey methods for assessment of Citrus tristeza virus incidence when Toxoptera citricida is the predominant vector. Phytopathology 89:487-494.

19. Hughes, G., Gottwald, T. R., and Levy, L. 2002. The use of hierarchical sampling in the surveillance program for Plum pox virus incidence in the United States. Plant Dis. 86:259-263.

20. Hughes, G., and Madden, L. V. 1992. Aggregation and incidence of disease. Plant Pathol. 41:657-660.

21. Hughes, G., and Madden, L. V. 1993. Using the beta-binomial distribution to describe aggregated patterns of disease incidence. Phytopathology 83:759-763.

22. Korie, S., Perry, J. N., Mugglestone, M. A., Clark, S. J., Thomas, C. F. G., and Mohamad Roff, M. N. 2000. Spatio-temporal associations in beetle and virus count data. Biol. Environ. Stat. 5:214-239.

23. Labonne, G., Lauriaut, F., Yvon, M., Quiot, J. B., Avinent, L., and Llacer, G. 1995. Aphids as potential vectors of Plum pox virus: Comparison of methods of testing and epidemiological consequences. Acta Hortic. 386:207-218.

24. Labonne, G., and Quiot, J. B. 2003. The behavior of alate aphids inside a Prunus orchard: An element to take into account for Plum pox virus spread? 12th Int. Symp. Apricot Culture and Decline. Acta Hortic. (In Press.)

25. Labonne, G., Quiot, J. B., Yvon, M., and Quiot-Douine, L. 1997. Immunoprinting: A quick and reliable method to measure efficiency of virus sources in field epidemiology. J. Plant Pathol. 79:135-141.

26. Labonne, G., Yvon, M., and Quiot, J. B. 1994. Dissemination du Plum pox virus par les pucerons: Analyse des vecteurs potentiels du virus dans un verger d'abricotiers. EPPO Bull. 24:681-690.

27. Levy, L., Damstegt, V., and Welliver, R. 2000. First report of Plum pox virus (Sharka disease) in Prunus persica in the United States. Plant Dis. $84: 202$.

28. Madden, L. V. 1989. Dynamic nature of within-field disease and pathogen distributions. Pages 96-126 in: Spatial Components of Plant Disease Epidemics. M. J. Jeger, ed. Prentice-Hall, Englewood Cliffs, NJ.

29. Madden, L. V., and Hughes, G. 1994. BBD-Computer software for fitting the beta-binomial distribution to disease incidence data. Plant Dis. 78:536-540.

30. Madden, L. V., and Hughes, G. 1995. Plant disease incidence: Distributions, heterogeneity, and temporal analysis. Annu. Rev. Phytopathol. 33:529-564.
31. Madden, L. V., Hughes, G., and Munkvold, G. P. 1996. Plant disease incidence: Inverse sampling, sequential sampling, and confidence intervals when observed mean incidence is zero. Crop Prot. 15:621-632.

32. Madden, L. V., Louie, R., Abt, J. J., and Knoke, J. K. 1982. Evaluation of tests for randomness of infected plants. Phytopathology 72:195-198.

33. Madden, L. V., Nault, L. R., Murral, D. J., and Apelt, M. R. 1995. Spatial pattern analysis of the incidence of Aster Yellows disease in lettuce. Res. Popul. Ecol. 37:279-289.

34. Morvan, G. 1988. The epidemiology of Plum pox virus in the apricot orchards of southern France: Description of computer tools and main observations. Acta Hortic. 235:263-270.

35. Nemchinov, L., and Hadidi, A. 1996. Characterization of the sour cherry strain of Plum pox virus. Phytopathology 86:575-580.

36. Nemchinov, L., Hadidi, A., Maiss, E., Cambra, M., Candresse, T., and Damsteegt, V. 1996. Sour cherry strain of Plum pox potyvirus (PPV): Molecular and serological evidence for a new subgroup of PPV strains. Phytopathology 86:1215-1221.

37. Perry, J. N. 1995. Spatial analysis by distances indices. J. Anim. Ecol. 64:303-314.

38. Perry, J. N. 1998. Measures of spatial pattern for counts. Ecology 79:1008-1017

39. Perry, J. N., Liebhold, A. M., Rosenberg, M. S., Dungan, J., Miriti, M., Jakomulska, A., and Citron-Pousty, S. 2002. Illustrations and guidelines for selecting statistical methods for quantifying spatial pattern in ecological data. Ecography 25:578-600.

40. Perry, J. N., Winder, L., Holland, J. M., and Alston, R. D. 1999. Red-blue plots for detecting clusters in count data. Ecol. Lett. 2:106-113.

41. Quiot, J. B., Labonne, G., Boeglin, M., Adamolle, C., Renaud, L. Y., and Candresse, T. 1995. Behavior of two isolates of Plum pox virus inoculated on peach and apricot trees: First results. Acta Hortic. 386:290-297.

42. Ridout, M. S., and Xu, X.-M. 2000. Relationships between several quadrat-based statistical measures used to characterize spatial aspects of disease incidence data. Phytopathology 90:568-575.

43. Roy, A. S., and Smith, I. M. 1994. Plum pox situation in Europe. EPPO Bull. 24:515-523

44. Shah, D. A., Bergstrom, G. C., and Ueng, P. P. 2001. Foci of Stagonospora nodorum blotch in winter wheat before canopy development. Phytopathology 91:642-647.

45. Smith, I. M., Mc Namera, D. G., Scott, P. R., and Harris, K. M. (eds.) 1992. Plum pox potyvirus. Pages $922-927$ in: Quarantine Pests for Europe. CAB International, Wallingford, UK.

46. Sokal, R. R., and den, N. L. 1978. Spatial autocorrelation in biology. 1. Methodology. Biol. J. Linn. Soc. 10:199-228.

47. Thackray, D. J., Smith, L. J., Cheng, Y., Perry, J. N., and Jones, R. A. C. 2002. Effect of strain specific hypersensitive resistance on spatial pattern of virus spread. Ann. Appl. Biol. 141:45-59.

48. Thresh, J. M. 1976. Gradients of plant virus diseases. Ann. Appl. Biol. 82:381-406.

49. Turechek, W. W., and Madden, L. V. 1999. Spatial pattern analysis of strawberry leaf blight in perennial production systems. Phytopathology $89: 421-433$

50. Upton, G., and Fingleton, B. 1985. Spatial Data Analysis by Example, Vol. 1. Point Pattern and Quantitative Data. John Wiley \& Sons, Chichester, West Sussex, England.

51. Varveri, C., Zintzaras, E., Dimou, D., and Di Terlizzi, B. 2001. Monitoring and spatiotemporal analysis of PPV-M spread in two apricot orchards in southern Greece. Acta Hortic. 550:129-133.

52. Wetzel, T., Candresse, T., Ravelonandro, M., Delbos, R. P., Mazyad, H., Aboul-Ata, A. E., and Dunez, J. 1991. Nucleotide sequence of the 3'terminal region of the RNA of the El Amar strain of Plum pox potyvirus. J. Gen. Virol. 72:1741-1746. 